\title{
PENGEMBANGAN E-MODUL KALFIS MATLAB GERAK VERTIKAL MENGGUNAKAN FLIP PDF CORPORATE EDITION
}

\author{
Ria Asep Sumarni, Nurfidah Dwitiyanti \\ Program Studi Teknik Informatika, Universitas Indraprasta PGRI Jakarta \\ Jl. Raya Tengah No. 80, Kel. Gedong, Kec. Pasar Rebo, Jakarta Timur 13760 \\ riaasepsumarni@gmail.com,nurfidah.pulungan@gmail.com
}

\begin{abstract}
ABSTRAK
Materi gerak vertikal yang disampaikan dalam kegiatan pembelajaran masih dalam bentuk Ppt dan video tutorial di Youtube. Agar dapat menarik kegiatan pembelajaran, maka diperlukan media pembelajaran yang lebih kreatif dan menarik. Sehingga pada penelitian ini, peneliti membuat media pembelajaran e-modul menggunakan flip pdf pada materi gerak vertikal yang berisi materi dan panduan membuat kalfis gerak vertikal menggunakan Matlab. Metode yang digunakan dalam penelitian ini adalah penelitian pengembangan atau Research and Development. Metode penelitian pengembangan adalah metode penelitian yang digunakan untuk menghasilkan suatu produk, serta menguji bagaimana keefektifan suatu produk. Dari hasil uji validasi ahli media dan ahli materi yang menyatakan bahwa e-modul kalfis matlab gerak vertikal menggunakan flip pdf Corporate Edition, layak digunakan sebagai media pembelajaran. Kemudian dilakukan uji coba kelompok kecil kepada mahasiswa untuk mengetahui kepraktisan e-modul, dan diperoleh hasil bahwa e-modul yang telah dibuat masuk dalam kriteria sangat praktis digunakan dalam pembelajaran membuat kalfis matlab gerak vertikal.
\end{abstract}

Kata Kunci: e-modul, flip pdf, gerak vertikal

\begin{abstract}
The vertical motion material delivered in learning activities is still in the form of Ppt and video tutorials on Youtube. In order to attract learning activities, more creative and interesting learning media are needed. So in this study, researchers made e-module learning media using flip pdf on vertical motion material which contained material and guidelines for making vertical motion kalfis using Matlab. The method used in this research is research and development. Development research method is a research method used to produce a product, as well as to test how effective a product is. From the results of the validation test of media experts and material experts who stated that the vertical motion kalfis matlab e-module using flip pdf Corporate Edition, was feasible to be used as a learning medium. Then a small group trial was conducted for students to determine the practicality of the e-module, and the results obtained that the e-module that had been made was included in the very practical criteria for use in learning to make vertical motion kalfis matlab.
\end{abstract}

Key Word: e-module, flip pdf, vertical motion

\section{PENDAHULUAN}

Pendidikan memiliki peranan sangat penting untuk menciptakan sumber daya manusia yang berkualitas baik. Pendidikan merupakan dasar manusia untuk menguasai ilmu pengetahuan dan teknologi. Proses pembelajaran mengalami pergeseran dari konvensional menjadi digital dengan alasan fenomena pemanfaatan teknologi di masyarakat yang kian tinggi (Nasrulloh \& Ismail, 2018). Pembelajaran pada hakikatnya adalah proses interaksi antara peserta didik dengan lingkungan, sehingga terjadi perubahan perilaku ke arah yang lebih baik (Arfani, 2016).
Penyampaian materi yang menarik tentunya akan membuat peserta didik lebih mudah untuk mengikuti. Peserta didik membutuhkan suatu sumber belajar untuk bisa memperkuat pemahaman, serta dapat dipahami secara mandiri, bahan ajar yang cocok tersebut adalah e-modul berbasis PBL yang dapat memuat teks, gambar, dan video (Malina et al., 2021).

Berbagai media pembelajaran diciptakan untuk memudahkan dan berinovasi dalam pembelajaran. Baik itu berupa video pembelajaran, game education, ataupun modul. Salah satu media yang dapat membantu dalam kegiatan pembelajaran adalah modul, terutama untuk kondisi daring 
saat ini diperlukan adanya elektronik modul (e-modul). E-modul telah banyak digunakan dalam pembelajaran fisika. E-modul dapat dirancang dengan menggunakan software $3 D$ pageflip professional, adobe animate $C C$, sigil, kvisoft flipbook maker, exe-Learning, aplikasi berbasis android atau integrasi aplikasi $C M S$ wordpress, situs berbagi video Youtube dan QMS classmarker (Saprudin et al., 2021).

Salah satu aplikasi untuk membuat e-modul berbasis filp pdf adalah flip pdf builder atau flip pdf Corporate Edition. Aplikasi flip pdf ini mudah digunakan secara online. Kelebihan dari flip pdf builder yaitu media flip pdf builder memiliki tampilan seperti buku bisa di geser maupun di slide. Konten didalamnya juga dapat diisi dengan animasi atau video, baik itu video offline maupun online, dan dapat pula diisi suara penjelasan materi yang kita rekam.

E-modul flip pdf yang dikembangkan memenuhi kriteria sangat valid, sangat praktis dan sangat efektif, sehingga e- modul berkualitas baik dan dapat digunakan dalam pembelajaran(Wulandari et al., 2021). Modul dapat memfasilitasi mahasiswa untuk belajar, baik dengan pendidik maupun secara mandiri, dan bahan ajar yang dikemas secara utuh dan skematis (Ardiansyah et al., 2016). Penelitian oleh (Solihudin JH, 2018) pengembangan emodul berbasis web pada materi listrik statis dan listrik dinamis dapat digunakan sebagai multimedia pembelajaran dan dapat meningkatkan pencapaian kompetensi pengetahuan peserta didik. Selain itu e-modul menggunakan aplikasi exe-learning layak digunakan untuk melatih literasi sains peserta didik (Muzijah et al., 2020). E- modul counter yang dikembangkan menggunakan aplikasi flip pdf professional layak digunakan dalam pembelajaran (Rindaryati, 2021).

Pembelajaran daring seperti saat ini, sangat diperlukan inovasi dalam pembelajaran. Para pendidik berusaha untuk lebih kreatif dalam menyampaikan materi ke peserta didik, agar materi yang disampaikan dapat diterima dengan baik. Materi fisika pada pokok bahasan gerak vertikal yang diajarkan kepada mahasiswa Teknik Informatika Universitas Indraprasta adalah berbasis Matlab. Sehingga dalam penyampaian materi diperlukan adanya panduan dalam menggunakan Matlab. Saat ini materi yang disampaikan dalam bentuk Ppt dan video tutorial di youtube. Agar dapat menarik kegiatan pembelajaran untuk mahasiswa tersebut, maka diperlukan media pembelajaran yang lebih kreatif dan menarik.

Sehingga pada penelitian ini, peneliti membuat media pembelajaran e-modul menggunakan flip pdf pada materi gerak vertikal yang berisi materi dan panduan membuat kalfis gerak vertikal menggunakan Matlab.

\section{METODE PENELITIAN}

Metode yang digunakan dalam penelitian ini adalah penelitian pengembangan atau Research and Development. Metode penelitian pengembangan adalah metode penelitian yang digunakan untuk menghasilkan suatu produk, serta menguji bagaimana keefektifan suatu produk tersebut, model penelitian pengembangan menggunakan model Borg \& Gall dalam (Sugiyono, 2015), namun hanya 8 tahap yaitu: Potensi dan masalah, pengumpulan data, desain produk, validasi desain, revisi, ujicoba produk, revisi produk, dan uji coba pemakaian. Penelitian ini sampai pada tahap ujicoba produk yaitu uji kepraktisan.

Tahap pertama yaitu melihat potensi dan masalah yang ada. Sampel yang digunakan dalam penelitian ini adalah mahasiswa Teknik Informatika Universitas Indraprasta PGRI kelas R3V tahun ajaran gasal 2021/2022. Mahasiswa ini mendapatkan mata kuliah fisika gerak yang didalamnya membahas materi gerak vertikal dan cara membuat kalkulator fisika menggunakan Matlab. Selama ini materi yang disampaikan dalam bentuk Ppt dan video Youtube. Sehingga perlu dibuatkan e-modul yang lebih menarik agar dapat memikat dalam kegiatan pembelajaran.

Tahap kedua yaitu pengumpulan data, peneliti melakukan wawancara kepada beberapa dosen yang mengampu mata kuliah fisika gerak. Selanjutnya adalah tahap ketiga, dimana peneliti mendesain e-modul yang akan dibuat sesuai dengan hasil observasi. Setelah membuat e-modul dilanjutkan ke tahap empat yaitu validasi desain yang dilakukan dengan memberikan angket validasi kepada ahli media dan ahli materi. 
Penilaian produk diuji dan dinilai oleh validator ahli media dan ahli materi. Untuk mengetahui rerata nilai, digunakan:

$$
\text { Persentase }(\%)=\frac{\text { Perolehan nilai }}{\text { nilai Maksimum }} \times 100 \%
$$

Angket validasi menggunakan skala likert dengan lima pilihan skor penilaian (Sugiyono, 2015) yaitu 1. Sangat tidak setuju, 2. Tidak setuju, 3. Ragu-ragu, 4. Setuju 5. Sangat setuju. Rumus yang digunakan untuk menghitung data hasil uji validasi ahli media dan materi adalah teknik analisis presentase menurut Arikunto dalam (Susanti \& Sholihah, 2021).

Tabel 1. Interval kriteria penilaian ahli media dan ahli materi

\begin{tabular}{cc}
\multicolumn{2}{c}{ ahli materi } \\
\hline Persentase & Kategori \\
\hline $81 \%-100 \%$ & Sangat Layak \\
$61 \%-80 \%$ & Layak \\
$41 \%-60 \%$ & Cukup Layak \\
$21 \%-40 \%$ & Kurang Layak \\
$<20 \%$ & Tidak Layak \\
\hline
\end{tabular}

Tahapan selanjutnya yaitu melakukan revisi jika terdapat revisi dari validator, dan langkah terakhir adalah melakukkan uji coba pemakaian yang diberikan kepada mahasiswa, angket respon mahasiswa digunakan untuk mengukur kepraktisan media yang dikembangkan peneliti. Angket respon diberikan melalui gform yang berisi butir pernyataan mengenai e-modul berbasis Flip PDF Corporate yang dikembangan peneliti. Hasil perolehan persentase dihitung dengan rumus berikut:

$$
\text { Persentase }(\%)=\frac{\text { Perolehan nilai }}{\text { nilai Maksimum }} \times 100 \%
$$

Tabel 2. Interval kriteria kepraktisan

\begin{tabular}{cc}
\hline Persentase & Kategori \\
\hline $81 \%-100 \%$ & Sangat Praktis \\
$61 \%-80 \%$ & Praktis \\
$41 \%-60 \%$ & Cukup Praktis \\
$21 \%-40 \%$ & Kurang Praktis \\
$<20 \%$ & Tidak Praktis \\
\hline
\end{tabular}

modul ini berisi materi gerak vertikal yang dilengkapi dengan panduan membuat kalfis gerak vertikal menggunakan matlab yang didalam materinya juga terdapat suara penjelasan materi serta terdapak video yang terhubung dengan youtube.

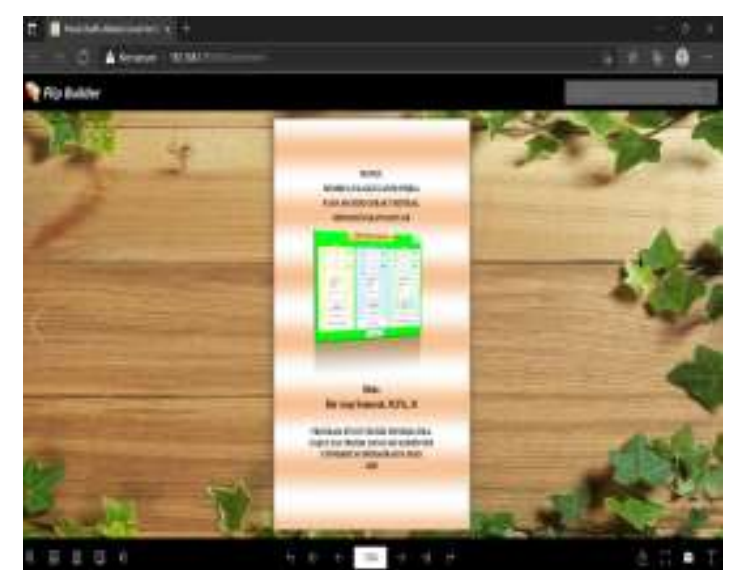

Gambar 1. Tampilan cover e-modul

Cover dari e-modul berisi judul modul, gambar kalfis matlab, nama penulis, instansi penulis, dan tahun terbit.

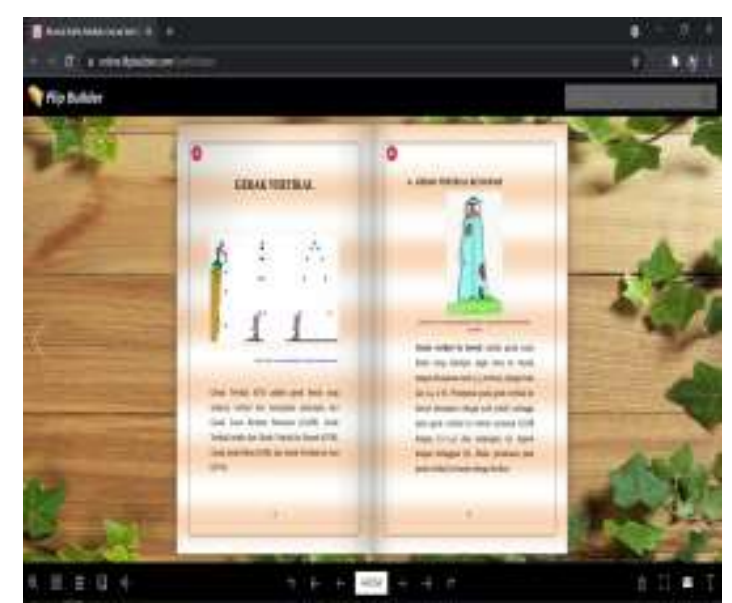

Gambar 2. Tampilan materi gerak vertikal

Pada mater tidak hanya dilengkapi dengan keterangan materi dan gambar, tetapi juga dilengkapi dengan suara yang menjelaskan materi tersebut. Sehingga peserta didik tidak hanya membaca tapi juga bisa mendengarkan penjelasan materi.

\section{HASIL DAN PEMBAHASAN}

Penelitian ini menghasilkan sebuah media pembelajaran e-modul kalfis matlab pada materi gerak vertikal dalam bentuk flip pdf. E- 


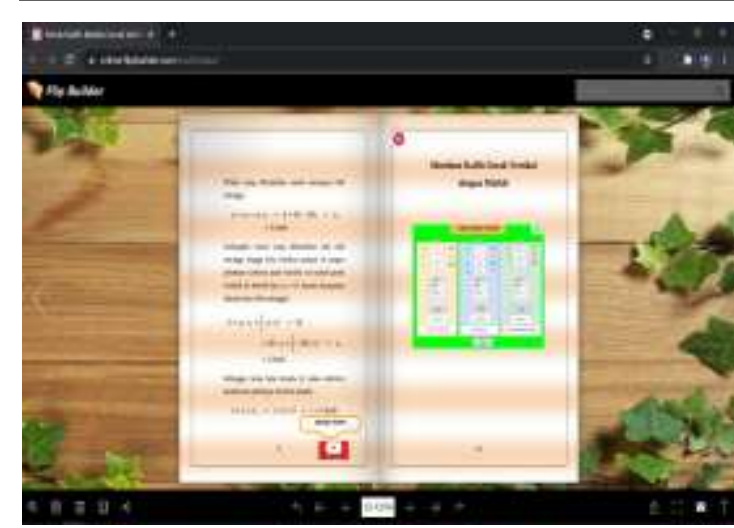

Gambar 3. Tampilan materi yang dilengkapi video

Diakhir penjelasan materi gerak vertikal dilengkapi dengan video pembelajaran yang terhubung ke Youtube. Sehingga peserta didik dapat melihat video penjelasan melalui youtube agar lebih memahami materi yang ada. Dalam video yang terhubung ke youtube juga terdapat tutorial pembuatan kalfis gerak vertikal menggunakan matlab. Sehingga bisa lebih mudah dalam memahami langkahlangkah membuat kalfis vertikal menggunakan matlab.

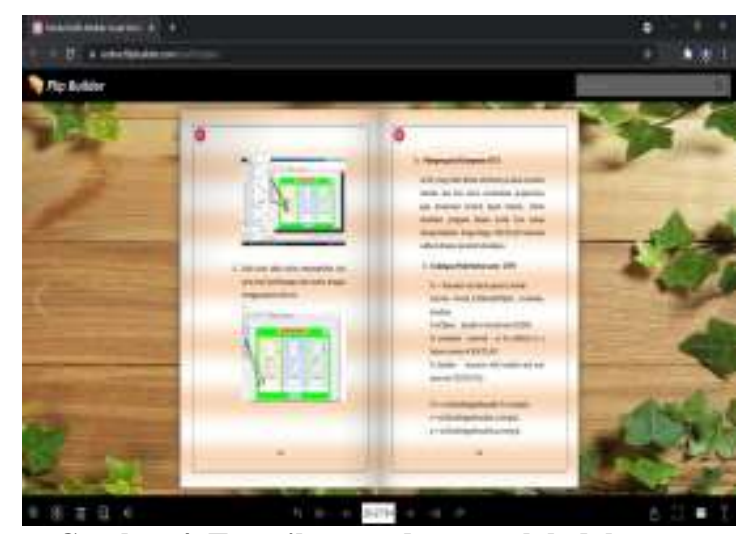

Gambar 4. Tampilan panduan matlab dalam emodul

Setelah melihat dari video Youtube mengenai tutorial pembuatan kalfis gerak vertikal, di dalam e-modul juga dilekngkapi secara rinci langkah-langkah membuat kalfis, dimulai dari perancangan figure matlab sampai dengan ke codingan. Sehingga bisa memudahkan dalam mengikuti petujuk dalam membuat kalfis gerak vertikal.

Hasil e-modul ini kemudian dilakukan uji coba kepada ahli media dan ahli materi dengan memberikan angket penilaian, dan diperoleh hasil sebagai berikut:
Tabel 3. Hasil validasi ahli media

\begin{tabular}{lccc}
\hline \multicolumn{1}{c}{$\begin{array}{c}\text { Aspek } \\
\text { Penilaian }\end{array}$} & $\begin{array}{c}\text { Skor } \\
\text { perolehan }\end{array}$ & $\begin{array}{c}\text { Skor } \\
\text { Maksimal }\end{array}$ & Persentase \\
\hline $\begin{array}{l}\text { Tampilan desain } \\
\text { Kemudahan } \\
\text { penggunaan }\end{array}$ & 14 & 15 & $93 \%$ \\
$\begin{array}{l}\text { Kegrafikaan } \\
\text { Kejernihan } \\
\text { suara dan video }\end{array}$ & 19 & 20 & $90 \%$ \\
\hline & 14 & 20 & $95 \%$ \\
\hline
\end{tabular}

Dari penilaian ahli materi diperoleh nilai dari aspek tampilan desain sebesar 93\%, aspek kemudahaan dalam penggunaan $90 \%$, aspek kegrafikan 95\%, dan terakhir pada aspek kejernihan suara sebesar 93\%. Sehingga diperoleh nilai rata-rata aspek penilain adalah 93\%, hal ini menyatakan bahwa dari penilaian ahli materi, e-modul kalfis matlab gerak vertikal menggunakan flip pdf termasuk dalam kategori sangat layak digunakan sebagai media pembelajaran. Ahli materi memberikan saran agar tidak hanya pada penjelasan materi yang diberikan suara, tetapi disetiap materi diperikan penjelasan dengan suara. Hal tersebut telah dilakuka revisi sehingga setiap materi terdapat penjelasan dengan suara.

Tabel 4. Hasil validasi ahli materi

\begin{tabular}{lccc}
\hline \multicolumn{1}{c}{$\begin{array}{c}\text { Aspek } \\
\text { Penilaian }\end{array}$} & $\begin{array}{c}\text { Skor } \\
\text { perolehan }\end{array}$ & $\begin{array}{c}\text { Skor } \\
\text { Maksimal }\end{array}$ & Persentase \\
\hline $\begin{array}{l}\text { Kesesuaian isi } \\
\text { materi }\end{array}$ & 18 & 20 & $90 \%$ \\
$\begin{array}{l}\text { Penulisan } \\
\text { rumus }\end{array}$ & 14 & 15 & $93 \%$ \\
Cakupan materi & 17 & 20 & $85 \%$ \\
\hline & Rata-rata & & $89 \%$ \\
\hline
\end{tabular}

Selanjutnya dari ahli materi diperoleh nilai 90\% dari aspek kesesuaian materi, 93\% dari aspek penulisan rumus, dan $85 \%$ dari aspek cakupan materi. Rerata dari aspek penilaian ahli materi diperoleh sebesar 89\%, hal ini menyatakan bahwa, e-modul kalfis matlab gerak vertikal menggunakan flip pdf termasuk dalam kategori sangat layak sebagai media pembelajaran.

Tahap terakhir dari penelitian ini setelah melakukan revisi dari ahli materi dan ahli media, peneliti melakukan uji coba kelompok kecil. Dalam hal ini peneliti memilih 10 mahasiswa sebagai kelompok kecil. Pada kelompok kecil mahasiswa diberi angket kepraktisan dengan 10 buah soal melalui gform, ini dilakukan untuk mengukur 
kepraktisan e-modul kalfis matlab gerak vertikal menggunakan flip pdf yang telah dibuat. Dari hasil angket kepraktisan diperoleh:

Tabel 5. Hasil angket kepraktisan

\begin{tabular}{|c|c|c|c|c|}
\hline Responden & $\begin{array}{c}\text { Skor } \\
\text { perolehan }\end{array}$ & $\begin{array}{c}\text { Skor } \\
\text { maksimal }\end{array}$ & $\begin{array}{c}\text { Persen } \\
\text { tase }\end{array}$ & Kategori \\
\hline mahasiswa1 & 40 & 50 & $80 \%$ & Praktis \\
\hline mahasiswa2 & 38 & 50 & $76 \%$ & $\begin{array}{l}\text { Praktis } \\
\text { Sangat }\end{array}$ \\
\hline mahasiswa3 & 44 & 50 & $88 \%$ & $\begin{array}{l}\text { Praktis } \\
\text { Sangat }\end{array}$ \\
\hline mahasiswa4 & 46 & 50 & $92 \%$ & $\begin{array}{l}\text { Praktis } \\
\text { Sangat }\end{array}$ \\
\hline mahasiswa5 & 45 & 50 & $90 \%$ & $\begin{array}{l}\text { Praktis } \\
\text { Sangat }\end{array}$ \\
\hline mahasiswa6 & 43 & 50 & $86 \%$ & $\begin{array}{l}\text { Praktis } \\
\text { Sangat }\end{array}$ \\
\hline mahasiswa7 & 48 & 50 & $96 \%$ & Praktis \\
\hline mahasiswa8 & 39 & 50 & $78 \%$ & $\begin{array}{l}\text { Praktis } \\
\text { Sangat }\end{array}$ \\
\hline mahasiswa9 & 47 & 50 & $94 \%$ & $\begin{array}{l}\text { Praktis } \\
\text { Sangat }\end{array}$ \\
\hline mahasiswa10 & 40 & 50 & $80 \%$ & Praktis \\
\hline & Rata-rata & & $86 \%$ & $\begin{array}{l}\text { Sangat } \\
\text { Praktis }\end{array}$ \\
\hline
\end{tabular}

Hasil angket kepraktisan yang diisi oleh mahasiswa, terdapat beberapa mahasiswa menyatakan praktis dan beberapa menyatakan sangat praktis. Setelah dihitung rerata perolehan nilai diperoleh sebesar $86 \%$, sehingga hal ini menyatakan bahwa e-modul kalfis matlab gerak vertikal menggunakan flip pdf masuk dalam kategori sangat praktis.

\section{SIMPULAN DAN SARAN}

Telah dibuat media pembelajaran berupa emodul kalfis matlab gerak vertikal menggunakan flip pdf Corporate Edition. Dimulai dari mengamati kebutuhan dalam kegiatan pembelajaran, sehingga dibuat emodul menggunakan flip pdf Corporate Edition agar bisa digunakan sebagai media pembelajaran. Setelah membuat e-modul dilakukan uji validasi kepada ahli media dan ahli materi yang menyatakan bahwa e-modul kalfis matlab gerak vertikal menggunakan flip pdf Corporate Edition, layak digunakan sebagai media pembelajaran. Kemudian dilakukan uji coba kelompok kecil kepada mahasiswa untuk mengetahui kepraktisan emodul, dan diperoleh hasil bahwa e-modul yang telah dibuat masuk dalam kriteria sangat praktis digunakan dalam pembelajaran membuat kalfis matlab gerak vertikal.
Saran untuk penelitian selanjutnya dikembangkan kembali e-modul flip pdf Corporate Edition dengan materi fisika yang lain, sehingga menambah inovasi dalam media pembelajaran.

\section{DAFTAR PUSTAKA}

Ardiansyah, R., Corebima, A. D., \& Rohman, F. (2016). Analisis Kebutuhan Pengembangan Bahan Ajar Perubahan Materi Genetik pada Matakuliah Genetika di Universitas Negeri Malang. Seminar Nasional Pendidikan Dan Saintek 2016, 1.

Arfani, L. (2016). Mengurai hakikat pendidikan, belajar dan pembelajaran. Pelita Bangsa Pelestari Pancasila, 11(2), $\quad$ 81-97. https://pbpp.ejournal.unri.ac.id/index.ph $\mathrm{p} / \mathrm{JPB} /$ article/view/5160

Malina, I., Yuliani, H., \& Syar, N. I. (2021). Analisis Kebutuhan E-Modul Fisika sebagai Bahan Ajar Berbasis PBL di MA Muslimat NU. Silampari Jurnal Pendidikan Ilmu Fisika, 3(1), 70-80. https://doi.org/10.31540/sjpif.v3i1.1240

Muzijah, R., Wati, M., \& Mahtari, S. (2020). Pengembangan E-modul Menggunakan Aplikasi Exe-Learning untuk Melatih Literasi Sains. Jurnal Ilmiah Pendidikan Fisika, $4(2), \quad 89$. https://doi.org/10.20527/jipf.v4i2.2056

Nasrulloh, I., \& Ismail, A. (2018). Analisis Kebutuhan Pembelajaran Berbasis Ict. Jurnal Petik, 3(1), 28. https://doi.org/10.31980/jpetik.v3i1.355

Rindaryati, N. (2021). E-Modul Counter Berbasis Flip Pdf pada Mata Pelajaran Penerapan Rangkaian Elektronika. Jurnal Imiah Pendidikan Dan Pembelajaran, 5(2), 192. https://doi.org/10.23887/jipp.v5i2.3124 0

Saprudin, S., Haerullah, A. H., \& Hamid, F. (2021). Analisis Penggunaan E-Modul Dalam Pembelajaran Fisika; Studi Literatur. Jurnal Luminous: Riset Ilmiah Pendidikan Fisika, 2(2), 38. https://doi.org/10.31851/luminous.v2i2. 6373

Solihudin JH, T. (2018). Pengembangan EModul Berbasis Web Untuk Meningkatkan Pencapaian Kompetensi Pengetahuan Fisika Pada Materi Listrik 
Statis Dan Dinamis Sma. WaPFi

(Wahana Pendidikan Fisika), 3(2), 51. https://doi.org/10.17509/wapfi.v3i2.137 31

Sugiyono. (2015). Metode Penelitian Pendidikan. In Bandung: Alfabeta.

Susanti, E. D., \& Sholihah, U. (2021). Pengembangan E-Modul Berbasis Flip Pdf Corporate Pada Materi Luas Dan Volume Bola. RANGE: Jurnal Pendidikan Matematika, 3(1), 37-46. https://doi.org/10.32938/jpm.v3i1.1275

Wulandari, S., Octaria, D., \& Mulbasari, A. S. (2021). Pengembangan E-Modul Berbantuan Aplikasi Flip Pdf Builder Berbasis Contextual Teaching and Learning. JNPM (Jurnal Nasional Pendidikan Matematika), 5(2), 389402. 